\title{
Effectiveness of Teacher Plus Psychosocial Model on Socio-Emotional Well-being of Secondary School Students: A Randomize Control Trail
}

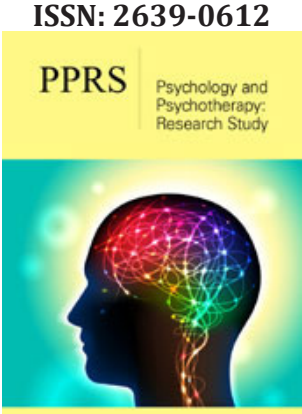

*Corresponding author: Sakila Yesmin, BRAC Institute of Educational Development (BIED), Bangladesh

Submission: 䦠 February 25, 2019

Published: :-warch 12, 2019

Volume 2 - Issue 2

How to cite this article: SakilaYesmin Mitul Dutta, Nishat Fatima Rahman, Dilruba Akther, Mamunur Rashid, Ratna Guha, et al. Effectiveness of Teacher Plus Psychosocial Model on SocioEmotional Well-being of Secondary School Students: A Randomize Control Trail. Psychol Psychother Res Stud . 2(2). PPRS.000535.2019.

DOI: 10.31031/PPRS.2019.02.000535

Copyright@BRAC Institute of Educational Development, This article is distributed under the terms of the Creative Commons Attribution 4.0 International License, which permits unrestricted use and redistribution provided that the original author and source are credited.

\section{SakilaYesmin ${ }^{1}$ *, Mitul Dutta ${ }^{1}$, Nishat Fatima Rahman ${ }^{2}$, Dilruba Akther ${ }^{3}$, Ma- munur Rashid ${ }^{3}$, Ratna Guha ${ }^{4}$, Khadiza Begum ${ }^{5}$, and Nusrat Jahan}

${ }^{1}$ Senior Lecturer, BRAC Institute of Educational Development, Bangladesh

${ }^{2}$ Assistant Professor, BRAC Institute of Educational Development, Bangladesh

${ }^{3}$ Research Associate, BRAC Institute of Educational Development, Bangladesh

${ }^{4}$ Field Researcher, BRAC Institute of Educational Development, Bangladesh

${ }^{5}$ Psycho-social Counsellor, BRAC Institute of Educational Development, Bangladesh

\begin{abstract}
Mental health and wellbeing are very crucial for personal, social, educational and economic benefits of children and adolescents. In Bangladesh 21\% adolescents are suffering from any one type of problem behavior. The main purpose of the study was to examine the effectiveness of the Teacher plus psychosocial model on socio-emotional well-being and knowledge and practice of SRHR of 6th grade students in junior secondary schools. It also explored the improvement of teachers' knowledge and practice. Mixed method study with randomized control design was conducted in 14 secondary schools in Dhaka city. A total 580 students of 6 th grade was randomly selected form the schools by two stage sampling where 280 students for each group. Students of 7 intervention schools received SRHR and psycho education delivered by the teachers. The intervention consists of 12 sessions on SRHR and psychosocial issues common adolescents: relationship, physical and metal changes, stress, anger, goal settings, exam phobia etc. Control group received nothing. Both quantitative and qualitative measures were taken at two pints -baseline and end line. The information was collected using the following tools- Socio-economic Status questionnaire (SES), General Health Questionnaire (GHQ), Strengths and Difficulties Questionnaire (SDQ), KAP questionnaire and FGD guideline. Findings showed that about $50 \%$ children were girls and the mean age was 12 years. After the intervention, it is found that the intervention group were more social than control groups (7.98 \pm 1.7 vs $7.63 \pm 1.8, p=0.012$ ) and improve their mental health status (GHQ: $10.35 \pm 4.7$ vs $11.25 \pm 5.1$, $\mathrm{p}=0.022$ ). The findings also showed that the knowledge level of students and teacher about psychosocial issues and SRHR was improved and they were practicing in their life. Both respondents shared that they were less stressed than before. Teacher shared that their attitude became more positive towards students and felt more flexible to talk to students and understand their feeling. Teachers stated that students' attendance level was increased, and they were more aware about themselves, their confidence level increased, the student those who didn't study regularly now study timely, they can make smart goals now. Both respondents shared that students were more aware of bulling and abuse than before. Parents also noticed the positive changes in their children. All respondents suggested training all teachers should be trained and the psychosocial intervention should be implemented in every school. Teaching 6 th grade students about SRHR and psychosocial issues helps to reduce stigma by increasing knowledge and change attitudes towards SRHR, bulling, and need for psychosocial support. The intervention would be a good and accessible mental health support model for adolescents
\end{abstract}

Keywords: Psychosocial model; Socio-emotional well-being; Secondary school

Abbreviations: SES: Socio-economic Status; SDQ: Strengths and Difficulties Questionnaire; GHQ: General Health Questionnaire; RCT: Randomized Controlled Design; SDs: Standard Deviation; FGD: Focus Group Discussion

\section{Introduction}

Childhood and adolescence are important periods for healthy development and good mental health. Despite the recognition of the significance of mental health promotion for 
children and adolescents, mental health and well-being remains a neglected public health issue, especially in low and middleincome countries La ncet, 2011. Study shows that socio-emotional distress and mental health problems of children and adolescents are more prevalent than they were in previous decades Elias \& Haynes 2008. Emotional and social problems of students not only impede educational, personal and social development but also may results in lifelong impairment functioning in social and personal life Rutter 1996. About $10 \%$ to $20 \%$ children in developed world are suffering from serious emotional and behavioral distress at least once Bird 1996 and the prevalence is almost the same or higher for the children of developing countries Nikapota 1991. Adolescents with socio-emotional difficulties have poor self-esteem and identity problem that are strongly associated with academic achievement. They have poor social relationship with parents and siblings, lack of coping skills with stress and depression. They also involve in school violence, aggression, bulling and disruptive behavior. Socio-emotional distressed students show non-aggressive conduct problems such as lying, stealing and disobedience. Depression has devastating effects on the life of adolescents affecting school performance, increasing antisocial behavior, self-harm, suicide, and impairing social interactions Fergusson \& Woodward 2002. High rate of self-harm and suicide are the leading causes of death in young people Lancet 2007. However, adolescents with higher level of socio-emotional well-being have higher level of academic achievement and are more engaged in school. Rabbani and Hossain 1999 reported that $13.4 \%$ of urban primary school children in Dhaka city, have been suffering from emotional, conduct and undifferentiated disorders. Recent data shows that $22 \%$ of students either lie in the borderline or in the abnormal band Hossain 2013.

\section{Objectives}

The hypothesis of the study is that the intervention will have positive effect on socio-emotional well-being and knowledge and practice of SRHRG of junior secondary school students. The main purpose of the study is to examine the effectiveness of the teacher plus psychosocial model on socio-emotional well-being and knowledge and practice of SRHR of $6^{\text {th }}$ grade students in secondary schools [1].

The specific objectives are:

1. To determine the effect of the intervention on students' in improving socio-emotional well-being and resilience.

2. To assess the improvement of students' knowledge and practice in SRHR and psychosocial skills.

3. To understand the improvement of teachers' knowledge and practice in psychosocial support to students.

\section{Methodology}

\section{Design}

The study was a single blind randomized controlled design (RCT) following mixed methods approach.

\section{Site}

The study was conducted in the secondary schools in Bonosree and Jatrabari in Dhaka city.

\section{Sample size}

Studies of school-based interventions report the effect size of at least 0.4 standard deviation (SDs) using brief mental health a questionnaire as proposed in order to detect effect size of $0.4 \mathrm{SD}$ with $80 \%$ power and $5 \%$ level of significance, $\mathrm{n}$ is 100 . Considering 40 students in sixth grade per school, assuming ICC $=0.04$, and 8\% drop out, the sample size is 276.48 or 278 students in each group. Therefore, we need $278 / 40=6.95$ or 7 schools to intervention group and 7 to control group, recruiting a total of 278 intervened and 278 control students and the total is 560 (round up) in Figure 1.

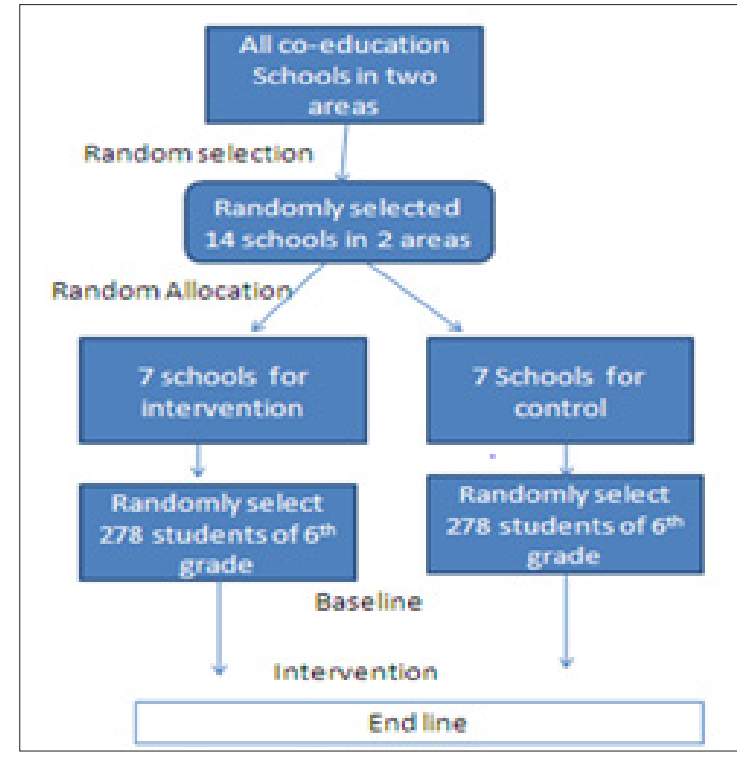

Figure 1: Design and sample frame.

\section{Sampling technique}

Sample were selected trough cluster random sampling technique at first 14 schools were randomly selected from the listed areas. From each area, equal number of schools was randomly assigned into two groups- intervention and control. There were 7 schools in each group. For assessment, a total 278 students were randomly selected for each group and the total sample size was 560 .

\section{Intervention}

The intervention was implemented in the $6^{\text {th }}$ grade class of the assigned secondary schools. In the intervention schools, the head teachers received a half day orientation on psychosocial intervention and 14 selected teachers of 7 schools received a five days training on the intervention. The intervention was consisted of 12 lessons on SRHR like menstruation management and psychosocial issues such as healthy relationship, mental sand stress, anger, bulling, time management, goal setting and self-care. The teachers conducted the sessions in the classroom. All the sessions were group sessions and taken in the regular school schedule [2]. 


\section{Instruments}

The following instruments will be used to collect data:

a) Socio-economic Status questionnaire (SES): Socio-economic information of students and teachers was collected by using SES questionnaire.

b) General Health Questionnaire (GHQ): The GHQ was administered to assess general mental health including depression McDowell \& Newell 1996. It is one of the most widely used psychometric measures in health and psychiatry and has good reliability and validity Goldberg et al. 1997.

c) Strengths and Difficulties Questionnaire (SDQ): The SDQ is a brief behavioral screening standardized questionnaire for measuring emotional and behavioral disorders in children and adolescents ranging from 2 to 17 years of age Goodman 1997; Mullick \& Goodman 2001. It exists in parent version, teacher version and a self-report version for children aged 11 years or above Goodman 1997. SDQ consists of five subscales, four of which assess problem behaviors relating to emotional symptoms, conduct problems, hyperactivity-inattention symptoms, and peer relationship problems, with the fifth assessing pro-social behaviors. It is a 3-point Likert scale with 25 items.

d) KAP questionnaire: This will be a semi-structured questionnaire. It was developed and used in the study to measure the students' knowledge, attitude and practice related to SRHR and psychosocial skills. Another short version of KAP for teachers was developed and used to collect information about knowledge and practice.

e) Focus Group Discussion (FGD) guidelines: Focus group discussions (FGD) with teachers, adolescent students and parents were conducted at the end line to know their understanding and perception towards the intervention.

\section{Data collection process}

Five field research assistants with 14-15 years education background / university degree and field experience were hired and trained on data collection for school survey and the instruments mentioned above to administer and collect data in baseline and end line. All FRAs received two weeks training on administration of psychological measurement tools including field practice and qualitative data collection techniques. During training, they received orientation on different tools and concepts like mental well-being. Inter-observer reliability of FRAs was done during training where each administered with 10 students. To check the quality of the data, the field supervisor monitored and supervised the FRAs during data collection regularly. One research supervisors received training on the assessment tools and supervision. For sample selection, FRAs conducted a school survey in February 2016. They visited schools in the BIED project areas and collected information. Then we selected schools randomly based on inclusion criteria from the school list and assigned them into intervention and control groups by using statistical software. For baseline and end line, FRAs collected the information from the students on socio-emotional status. KAP, GHQ and SDQ. All the tools were self-reported. In addition to that, two FGDs with teachers, two FGDs with parents and two FGDs with students were conducted at the end line [3].

\section{Data management and analysis}

Before entering into computer, data will be checked and cleaned in the data sheet manually. All data were entered into computer using SPSS 16 and checked for normality. Frequencies and mean scores were calculated for each group. To compare the t-test was used applied for continuous variables and $\mathrm{X}^{2}$ test was used for dichotomous variables. Correlation analysis also used to see the relationship between variables. To examine the intervention effect, multiple linear regressions used to control for baseline measures and any confounding variables. In this study, the qualitative information was collected through FGDs and IDIs. The data were management and analyzed were done following to the content analysis approach.

\section{Ethical consideration}

The study draws on ethical guidelines developed by BIED, BRAC University. Students and teachers were informed of the study procedures, risks and benefits. They could ask questions and to make a voluntary decision about their participation. All information about study participants were kept in strict confidence and their identities were kept anonymous by using identifier codes on data files and storing the lists of participants and their identifier codes separately in a locked cabinet. The names of participants and any other personal means of identification were not used in the data analysis and dissemination, thereby ensuring that personal identities are kept anonymous. They were asked to communicate with the research team for any query [4].

\section{Results}

Table 1: Characteristics of adolescents and their families in intervention and control groups

\begin{tabular}{|c|c|c|c|}
\hline Variables & $\begin{array}{l}\text { Intervention } \\
\quad(n=280)\end{array}$ & $\begin{array}{l}\text { Control } \\
(n=280)\end{array}$ & p-value \\
\hline $\begin{array}{l}\text { Parental Charac- } \\
\text { teristics }\end{array}$ & Mean \pm SD or $\%$ & Mean $\pm \mathrm{SD} / \%$ & \\
\hline Mother's age & $36.19 \pm 5.9$ & $36.53 \pm 5.72$ & ns \\
\hline $\begin{array}{l}\text { Mothers as home } \\
\text { makers }\end{array}$ & $94.3 \%$ & $95.4 \%$ & ns \\
\hline Father's age & $43.30 \pm 7.15$ & $43.55 \pm 7.12$ & ns \\
\hline $\begin{array}{l}\text { Father with no reg- } \\
\text { ular employment/ } \\
\text { Day Labor }(\%)\end{array}$ & $25.0 \%$ & $21.8 \%$ & \\
\hline \multicolumn{4}{|l|}{$\begin{array}{l}\text { Student character- } \\
\text { istics }\end{array}$} \\
\hline Age & $12.16 \pm 1.08$ & $12.10 \pm .94$ & ns \\
\hline Female & $49.6 \%$ & $50 \%$ & ns \\
\hline
\end{tabular}


Table- 1 shows that the mean age of mothers is 36.19 and 36.53 years in the intervention and control groups respectively. More than 90 percent mothers of the adolescents are not employed. The mean age of fathers of both groups is around 43 years in both groups. About 25 percent and 21.8 percent fathers were day labors. The mean age of students was 12 years in the both groups and about 50 percent were female (Table 1). The result showed that there was no significant difference in the demographic characteristics of the adolescents and their families.

\section{Quantitative data analysis}

The Table 2 reflects that the SDQ scores were 12.43 and 11.99 of the intervention and the control group respectively at the baseline. The mean scores and SD of the pro-social behaviors of adolescents were $7.1 \pm 1.9$ and $7.3 \pm 1.8$ of the intervention and the control groups respectively the mean scores and SD of the GHQ were $10.5 \pm 4.8$ and $11.16 \pm 5.0$ of intervention and control groups. There was no significant difference in both SDQ and GHQ between the group at the baseline except pro-social behaviors $(\mathrm{p}=0.066)$. At the endline, the SDQ mean scores and SD were 11.34 \pm 5.0 in the intervention group and $11.43 \pm 5.2$ in the control group respectively. The mean scores and SD of pro-social behavior of both intervention and control groups were $7.98 \pm 1.7$ and $7.63 \pm 1.8$. The adolescents of the intervention group were more social compare to the control adolescents $(\mathrm{p}=0.012)$. It is found that the mean scores and SD of GHQ of intervention group was significantly higher than the control adolescents (10.35 \pm 4.6 vs11.25 $\pm 5.1, \mathrm{p}=0.022)$.

Table 2: Characteristics of students in intervention and control groups.

\begin{tabular}{|c|c|c|c|c|c|c|}
\hline \multirow[b]{2}{*}{$\begin{array}{l}\text { Scales and Sub- } \\
\text { scale }\end{array}$} & \multicolumn{3}{|c|}{ Baseline } & \multicolumn{3}{|c|}{ End line } \\
\hline & Intervention & Control & p-value & Intervention & Control & p-value \\
\hline SDQ Sub-scale & $(n=280)$ & $(n=280)$ & & $(n=279)$ & $(n=277)$ & \\
\hline $\begin{array}{c}\text { Emotional Problem } \\
\text { Scale }\end{array}$ & $3.53 \pm 2.1$ & $3.34 \pm 2.1$ & Ns & $3.49 \pm 1.9$ & $3.10 \pm 2.1$ & Ns \\
\hline $\begin{array}{l}\text { Conduct Problem } \\
\text { Scale }\end{array}$ & $2.10 \pm 1.7$ & $2.07 \pm 1.6$ & ns & $1.91 \pm 1.6$ & $1.87 \pm 1.7$ & ns \\
\hline Hyperactivity Scale & $3.29 \pm 1.8$ & $3.16 \pm 1.8$ & ns & $2.91 \pm 1.7$ & $3.17 \pm 1.8$ & 0.085 \\
\hline Peer Problem Scale & $3.51 \pm 1.8$ & $3.42 \pm 1.7$ & ns & $3.08 \pm 1.7$ & $3.29 \pm 1.7$ & ns \\
\hline Pro-social behavior & $7.07 \pm 1.9$ & $7.35 \pm 1.8$ & 0.066 & $7.98 \pm 1.7$ & $7.63 \pm 1.8$ & 0.012 \\
\hline SDQ Full Scale & $12.43 \pm 5.4$ & $11.99 \pm 5.5$ & ns & $11.34 \pm 5.0$ & $11.43 \pm 5.2$ & ns \\
\hline GHQ Full Scale & $10.55 \pm 4.8$ & $11.16 \pm 5.0$ & ns & $10.35 \pm 4.6$ & $11.25 \pm 5.1$ & 0.022 \\
\hline
\end{tabular}

Table 3: Regression of GHQ on group effect.

\begin{tabular}{|l|l|l|l|l|l|l|l|l|}
\hline Model & R square & B & Std. Error & Beta & T & Sig. & Partial & Part \\
\hline Pro-social & & & & & & & \\
\hline Scale & .010 & .354 & .150 & .100 & 2.37 & .018 & $.100^{*}$ & $.100^{*}$ \\
\hline GHQ & .009 & -.948 & .413 & -.097 & -2.296 & .022 & $-.097^{*}$ & $-.097^{*}$ \\
\hline
\end{tabular}

Adjusted $\mathrm{R}^{2}$ value in the Table 3 indicates that the model (Teacher plus psycho-social Intervention) was significantly explained $0.8 \%$ variance on Pro-social and GHQ. However, part correlation co-efficient indicate that the unique contribution to the intervention was $9.7 \%$ students' mental health status and $10 \%$ for pro-social behavior. Dependent Variable: Pro-social and GHQ at endline; Group: 1= Control \& 2= Intervention; Low score means better mental health status $[5,6]$.

${ }^{*} \mathrm{CI}=95 \%$, Adjusted $\mathrm{R}^{2} 0.008$ for both GHQ and pro social.

\section{Qualitative findings}

Theme 1: Understanding about psychosocial and SRH issues of adolescent students: The FGD data reveal that most of teachers and students had no clear concept about mental health or psychosocial issues before intervention. Students shared that they have limited knowledge about the changes during puberty. After the intervention they knew more about SRH and psychosocial issues like management of stress, anger and time, goal setting, healthy relationship, abuse, bulling and exam phobia. Adolescents mentioned that their stress has been reduced than before. They also shared that they can manage anger and stress better than before by using different techniques like relaxation, listening radio or keep silent. They said they do not bully now as they learnt that these are kind of harassment and their teacher prohibit them bullying others. In the past they were afraid and tensed for examination. But now they get rid of exam phobia because of proper planning activities. They complete their coursework and attend in class regularly and they overcome the fear of examinations. Most of the teachers said that they were not clear about the word "psychosocial" before training, but now they knew about that. One teacher said, "Before the training I used to listen to children but now she can feel in her heart after listening and can go much deeper of that word".

Theme 2: Mindset changes of the teachers, students and parents about psychosocial and SRH issues of adolescents: Most of the 
teachers mentioned that after getting the training they feel their attitude are positive than before, they are more approachable, friendly and open-minded. They feel teachers are flexible to talk, try to understand student's feelings and discuss issues easily with students and family members. After getting the sessions, they are now more open and feel free to talk and share their problems with teachers. An observation about girls sharing her problem was narrated by a teacher as following: "a girl of grade six seems depressed in class, after taking these sessions, one day the girl came to me and told that she has some family problems. After a while, she shared that problem with me. I listened to her and provide couple of suggestions. Nowadays, I observed the girl is much happier in the class. As a teacher, I feel satisfied to look at this scenario". Most of the teachers said that previously there is a gap between teacher and adolescent students which have been reduced a lot after the sessions. They also share that students are more open and feel free to talk and share their problems with teachers. Students are more aware about bulling and abuse than before. Teachers also mentioned that girls are now aware about the changes and menstrual management and follow the information given in the class and so they take fewer days off during that time. Teachers said students previously could not talk about these issues but now they talk about it. Female students did not attend school during menstruation period; they used to take three to four days off, but after the session, they are now aware about the changes and menstrual management and hygiene. A teacher happily mentioned: I get calls from guardians (mothers). They said, "Madam, you did what I supposed to do, I felt embarrassed to discuss these information with my child, but you have discussed these in the class. I feel good that now they are well informed regarding the menstrual management at that period".

Theme 3: Effects of Psycho-education: All respondents emphasized that psycho-education should be thought in every school. If the psycho-education would be taught in schools, it would be helpful for both students and teacher. It helps to improve relationship with peer, and teachers and interaction between students and the teachers and parents. Adolescents are become skilled to manage stress, ager and time that would help to perform better in school. Both teacher and parents shared that they have noticed some changes among their adolescents. Some parents said that boys became friendly and less angry than before. Teachers also respond that, during exam time students gets nervous and feared before, but after getting extra classes of psycho-education they knew about exam phobia and goal setting, now students can construct their lesson plan according to their syllabus, can make a smart goal to achieve their target and the consequences are- their fear about exam decrease. They get benefited most, they are more aware about themselves, their confidence level increased.

\section{Discussion and Conclusion}

The purpose of the study was to examine the effectiveness of the teacher plus psychosocial model on socio-emotional wellbeing and knowledge and practice of SRHR of $6^{\text {th }}$ grade students in secondary schools. About 0.7 percent students was dropped out in the study which is very minimal. In the study, socio-emotional well-being of the students was measured by SDQ and GHQ. There is no significant difference in the demographic characteristics of the adolescents and their families between the control and intervention group at baseline. The findings show that the SDQ scores was not significantly higher at the end line and no difference between the intervention and control groups. However, pro-social behaviors of the students of the intervention group was improved significantly after the intervention (intervention vs control: $7.98 \pm 1.7$ vs7.63 \pm 1.8 . and $\mathrm{p}=0.012$ ). The students of the intervention group are more social and cooperative compare to their counterpart which is one of the key aspects of socio-emotional well-being. The findings also reveal that the mean score of the GHQ was significantly reduced in the intervention group after the intervention $(\mathrm{p}=0.022)$. The intervention supported to reduce general mental health problem like anxiety, depression of the students.

It is also found that the intervention has effective to improve the knowledge and practice of adolescents regarding SRHR and psychosocial issues like anger and stress management and to build healthy relationship with parents, peers and teachers as well as socio-emotional well-being of $6^{\text {th }}$ grade adolescents.

The intervention has developed the mindset of students and as a result they tend to share their mental and physical abuses with peers, teachers and parents with being less hesitant. It made them feel comfortable to speak up about street harassment, mental and physical abuses. It also helps to minimize the power gap among students in class which results to students' talk more about SRHR and psychological issues. The psycho-education has helped students to overcome nervousness before the exam and prepared them to manage the stress of exam phobia.

After the intervention, students have become aware about menstrual hygiene. As a result, they became regular to school during their menstruation period. Beside menstrual hygiene, they also feel free to share menstrual problems with teachers and parents which they have usually never done before the intervention. In conclusion, school based SRHR and psycho-education help to reduce stigma by increasing knowledge and change attitudes of adolescents towards SRHR, bulling of adolescents and address the need for psychosocial support.

\section{Acknowledgment}

We gratefully acknowledge the participation of all teachers, students of the schools and their families in Dhaka. We also thank the members of the study team, and testers. We extend our gratitude to the staffs of Head teachers of the schools and thank to Nuffic to provide financial support to conduct the study.

\section{References}

1. Hossain S (2013) A study of determining the relationship between academic achievement and problem behavior of urban secondary school students in Bangladesh. The International Journal of Social Science 8: $1-10$.

2. Jennings PA, Greenberg MT (2009) The prosocial classroom: Teacher social and emotional competence in relation to student and classroom outcome. Review of Educational Research 79(1): 491-525.

3. Kamal SMM, Hassan CH, Alam GM, Ying Y (2015) Child marriage in Bangladesh: Trends and determinants. J Biosoc Sci 47(1): 120-139. 
4. Kaplan DS, Liu RX, Kaplan HB (2005) School related stress in early adolescence and academic performance three years later: The conditional influence of self-expectations. Social Psychology of Education 8(1): 3-17.

5. Unicef (2008) Bangladesh.
6. Ilyas QSM, Aeysha M (2001) Bengali version of Goldberg General Health Questionnaire (GHQ). Unpublished manuscript, Department of Psychology, Dhaka University, Dhaka.

For possible submissions Click below: 